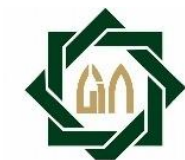

UIN SUNAN AMPEL

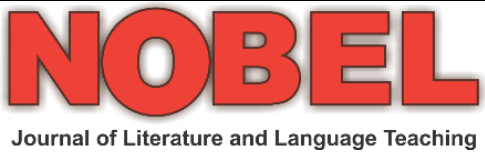

Volume 10, Number 2, September 2019, 103-116 available at http://jurnalfahum.uinsby.ac.id/index.php/nobel/article/view/nomorurut

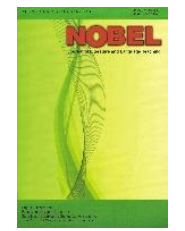

DOI: 10.15642/NOBEL.2019.10.2.103-116

\title{
UNCOMMON WORD ORDER OF YODA IN STAR WARS MOVIE SERIES: A SYNTACTIC ANALYSIS
}

\section{Yuliyana $^{1}$, Barli Bram ${ }^{2 凶}$}

Sanata Dharma University, Jalan Moses Gathotkaca, Catur Tunggal, Sleman, Yogyakarta 55281

\begin{tabular}{l}
\hline Article Info \\
\hline Article History: \\
Received July 2019 \\
Accepted August 2019 \\
Published September 2019 \\
\hline Keywords: \\
content analysis; syntactic \\
analysis; word order; Yoda; \\
Star Wars \\
\hline
\end{tabular}

\section{Abstract}

This paper analyzes Yoda's syntax order to discover the word order which occurs in his speeches and the factors affecting his preferred syntax. Data were collected from Yoda's utterances in George Lucas' Star Wars saga. Yoda, who speaks English, expresses his thoughts in an unusual structure which might not be recognized by the existing rules of syntax. Instead of speaking in the traditional Subject-Verb-Object syntax, Yoda speaks in Object-Subject-Verb and Verb-Object-Subject syntax. This study employs content analysis, diving into seven Star Wars movies from the Saga. Out of 169 sentences Yoda uttered, the researchers discovered three factors affecting his preference to use the unusual syntax, namely Yoda's origin, personality and traits, and power and abilities. 


\section{INTRODUCTION}

Syntax, by definition, is a set of rules that governs the arrangement of words to create a structured, well-functioning, and understandable sentence. Word order (henceforth, WO) is essential, not only in English but also in other languages, as it can affect the intended meaning of a sentence. In other words, syntax is crucial when it comes to communicating ideas. Failing to follow the rules of syntax is the same as risking to convey a different meaning. Hence, it can be argued that the rules of syntax are absolute in structuring a sentence.

A study on syntax serves numerous purposes, from general humanistic to social inspirations. It can assist English learning by empowering us to break down the structure of English sentences efficiently and unequivocally. Studying WO includes numerous syntactic models, which generally fall into two models: to consider WO as a dynamic basic property of sentences and to view WO as an autonomous issue. Chomsky's transformational-generative language structure is typical in the principal model. The representatives of the last models are useful sentence structure, lexical utilitarian language, and word syntax. Conceptually, "syntax is concerned with the ways in which words can be organized into sentences and how sentences are understood" (Bauer, 2017, p. 12). The term syntax may refer to "the component of a grammar which determines how words are combined together to form phrases and sentences" (Radford, 2004, p. 247). In English, grammar plays a crucial role and contains numerous rules, for example, notional and grammatical concord or agreement between a subject and finite verb in the present tense. "Grammatical agreement, in general, has become the focus of the English language learning” (Djami, Setiawan, \& Bram, 2019, p. 77).

Previous works in WO have been done in various comparative studies between English and other languages, such as Chinese and Persian. Taking as an example, a comparative study between English and Chinese by Zhao and Cao (2016) highlighted the likenesses and the contrasts between English and Chinese WO from English and Chinese sentences in a story. In perspective on the figure-ground hypothesis, English supports intellectual model from figure to ground, while Chinese supports the order from ground to figure. The analysis of the article concludes in the fact that English and Chinese WO affects various cognitive models. A similar study of English and Persian WO by Izadi and Rahimi (2015) aimed to discover likely relationships and decent varieties between the two languages. They investigated each language's qualities and found that the WO of English and Persian demonstrates various contrasts. Persian exhibits a more lenient WO while English is a little strict when it comes to SVO. 
In this study, the researchers analyzed a movie character, named Yoda, notably for his patterns of speech in OSV and VOS, which are against the traditional SVO syntax. Yoda is a supporting character in Star Wars saga, who has reprised his role in seven movies as of September 2018. This study transcribed and analyzed his dialogues to understand better the reasons behind his breaking the traditional syntax. The researchers believe that this study carries an important role both in the linguistic world and movie industry, given its analysis on words and character development. As for its purpose in the educational field, it is expected that this paper could invoke future researchers to conduct a similar study that employs linguistics, along with other subjects from different areas of expertise. The research question in this paper was formulated as follows: What uncommon word order does Yoda utilize in the Star Wars movie series?

\section{REVIEW OF LITERATURE}

Fundamental WO is grounded on properties of a specific sort of sentence. The kind of sentence we are keen on is the revelatory sentence, that is, a sentence which creates an impression about an option that is, instead of being posing an inquiry or issuing an order. Moreover, it is a final sentence which states, in all respects freely, that something has planned something for something different. "Word order is divided into three parts: the order of major sentence elements, the ordering within a noun phrase, and whether prepositions or postpositions are used. The first is given in terms of the ordering of S[ubject] V[erb] and O[bject] ..." (Bauer, 2007, p. 226).

The sentences we are intrigued can regularly be dissected as having three constituents: a subject (S), a verb (V) and an object (O). There are six coherently potential varieties by which these constituents can be ordered, and these are SOV, SVO, VSO, VOS, OVS, and OSV. In many languages, one of these six orders can be considered as being, freely, the most widely recognized, normal or significant. For example, most English revelatory sentences use SVO WO instead of any of the other five, although there are special cases. Newmeyer (1998) recognizes, at any rate, the accompanying techniques for picking the fundamental WO for a language, which are: "Choose the order with the highest text frequency; Choose the order in which $\mathrm{S}$ and $\mathrm{O}$ are full NPs; Choose the order that carries the fewest special presuppositions; Choose the order associated with the most basic intonation contour; Choose the order associated with the least overall syntactic or morphological elaboration; Choose the order at a motivated underlying level of syntactic structure.” Unlike English, “... there seems little doubt that OVS is the basic order in Hixkaryana ..." (Derbyshire, 1977, p. 598). Hixkaryana 
"is a member of the Carib linguistic family and is spoken by groups located on the Nhamunda and Mapuera rivers in northern Brazil" (Derbyshire, 1977, p. 591). Finnish, as Kaiser and Trueswell (2004, p. 113) point out, is "an articleless flexible word-order language with canonical SVO order, word order can be used to encode the given/new distinctions ..."

According to Maurits (2011), there are a few noteworthy cross-semantic investigations of fundamental WO, fixated on those studies which have shown up endeavors at portraying the watched frequencies. The various studies checked on the measure of languages analyzed, the specific language inspected, the way wherein those specific languages were inspected, and the technique by which every language's essential WO was considered.

\section{Greenberg}

In 1963, Greenberg first conducted the study in a modern WO typology. It is the beginning of the latest enthusiasm for WO universals. A large number of the universals proposed in this paper were deciphered from little scale research of 30 languages, yet the essay's informative supplement really incorporates a bigger example of 142 languages, and fundamental WO is upheld by every one of them. Greenberg clarifies that the languages in the littler research were picked for ease of use. There is no further clarification in portraying how the other languages for the bigger research were gathered. Despite the fact that, regardless of whether it appears to be ideal to take a gander at a bigger convenience sample as a matter of course, since the way that half portion of the legitimately conceivable essential WOs are confirmed, meaning it couldn't be considered as an assorted variety test and does not seem to be purposefully built to be equivalent. It merits alluding to, however, that for an accommodation overview, particularly thinking about its diminutive size, the hereditary and areal range is genuinely broad. SOV is by a long shot the most successive WO in the sample, at $45 \%$, trailed by SVO at $37 \%$ and afterward VSO at simply $17 \%$. The VOS, OVS and OSV WOs are not totally recorded in Greenberg's study, which is completely commonplace for the study of the time. Greenberg (1963, p. 76) concludes that of the six logically probable sequences of main constituents (SVO, SOV, VSO, VOS, OSV, OVS), "only three normally occur as dominant orders. The three which do not occur at all, or at least are excessively rare, are VOS, OSV, and OVS" (see also McCawley, 1970; Hannay, 1991).

\section{Ruhlen}

In 1975, Ruhlen introduced a study of about 700 languages, 435 of which are basic WO data. This study is significant as it surveys at least one language for all six of the logically possible basic WOs. At the time of publication, such a study was limited. No further description is provided on how the languages employed were selected. However, since the 
study is presented as part of a "guide to the languages of the world," and since it includes examples of all six of the logically possible basic WOs, it seems ideal to review it as a diversity study than either practicality or comparable study. While VOS and the object-initial languages are all discussed in Ruhlen's list, "SOV, SVO, and VSO dominate the sample," and in the same order as in Greenberg's study, at 51\%, 36\% and $10 \%$ respectively.

\section{Hawkins}

Later, Hawkins in 1983 constructed a study by selecting Greenberg's study of 142 language study, further increasing the number into 336 languages. Hawking explained that the study could be described as a usability sample, with the selection of languages indicating the correspondents' interests and competence, accessibility of sources of information, and the original Greenberg study. However, in this study, the correspondents were persuaded not to work on the same language of family or group so that the genetic diversity would be increased. The absence of object-initial languages in the study is fascinating at the time time of publishing. Even so, there is a VOS WO in the example, so it shows more diversity than Greenberg's original study. The proportional frequencies of the basic WO in Hawkin's study are quite similar to Ruhlen's study, with SOV, SVO, and VSO dominating heavily. Hawkins' survey distribution: "SOV $(52 \%)>\operatorname{SVO}(32 \%)>\operatorname{VSO}(13 \%)>\operatorname{VOS}(2 \%)=\operatorname{OVS}(0 \%)=$ OSV (0\%)."

\section{Tomlin}

Tomlin (1986) introduced an attentive-based proportional study, researching 402 languages. These 402 languages were tested from a larger database of basic WO on 1063 languages of smaller examples. These samples of languages were delivered by continually drawing 402 languages in an autonomous and unsystematic means from the greater database, as well as experimenting with 402 languages samples for remarkable areal partialities. Tomlin did this process over and over again until a sample without any partialities was delivered. Testing for partialities was directed using the Kolmogorov goodness-of-fit-test, issued from genetic and areal information. Fundamentally, Tomlin's study shows an attentive use of proportional sampling, causing it a remarkably more ideal study for present purposes than Greenberg's, Ruhlen's, or Hawkins'.

Tomlin's study presented languages demonstrating all six of the feasible basic WOs except for OSV. Similar to earlier studies, the subject-initial orders prevail strongly, with VSO being by far the next most repeated and VOS and OVS only a bit demonstrated. Tomlin's survey distribution: "SOV $(45 \%)=\mathrm{SVO}(42 \%)>\operatorname{VSO}(9 \%)>\operatorname{VOS}(3 \%)=\mathrm{OVS}$ $(1 \%)>\operatorname{OSV}(0 \%)$. 


\section{Dryer}

In Dryer (2008) study, there existed a sizeable model that consisted of 1057 languages. As this study was a component of an effort at categorizing all languages, the initial assumption was that it would be fairly similar to proportional, partially similar to the study of Greenberg, Ruhlen, and Hawkins. Dryer's study was simply the one in which the entire six of logically possible orders were demonstrated, with OSV languages being presented for the first time despite its exceptionally low amounts. According to all the previous studies of threeword orders, SOV, SVO, and VSO are dominating with $97 \%$ of languages, with SOV and SVO dominating at 88\%. Dryer's study distribution: "SOV (47\%) > SVO (41\%) > VSO (8\%) $>\operatorname{VOS}(2 \%)>\operatorname{OVS}(1 \%)>\operatorname{OSV}(0 \%)$."

Even though the accurate proportionate frequencies of different basic WOs could be noticed to several studies, in some points by up to as much as $10 \%$, it is evident that when it approaches levels the contrastive basic WOs by rate of occurrence, there is an excellent agreement. Each study covered upon was steady with the ranking "SOV $>$ SVO $>$ VSO $>$ VOS $\geq(\mathrm{OVS}$, OSV)." The comparative ranking of OVS and OSV was the barely setting that there was any variation. The most frequently stated considerable ranking is "OVS > OSV," and indeed the ranking "SOV $>\mathrm{SVO}>\mathrm{VSO}>\mathrm{VOS}>\mathrm{OVS}>\mathrm{OSV}$ " has mainly been drawn as the proper complete ranking in the literature.

\section{METHOD}

This study applied content analysis as the methodology. According to Ary, Jacobs, and Razavieh (2002), content analysis emphasizes studying and describing recorded material to understand human behavior. The purpose of this method is to recognize the relative importance of particular issues. In this study, all of Yoda's dialogue in seven movies are transcribed and analyzed, particularly on the syntax. The researchers provide a comparison table between Yoda's syntactic constructions, namely OSV and VSO.

According to Ary et al. (2010), the first step involved in a content analysis research is to specify the phenomenon to be examined. The researchers also followed three steps of analyzing a document proposed by Creswell (2007). The first step is preparing and organizing. The researchers downloaded the subtitle for Star Wars movies which Yoda appeared and watched all the movies with subtitles. Then the next step is coding where the researchers selected the media from which the observations were to be made, namely the uncommon syntax found in the Star Wars movies, which then led to deciding on the sampling plan to be used for obtaining a chosen sample of the movies. There were seven movies where 
Yoda appeared. The last step was analyzing the data, namely all selected samples of Yoda's dialogues by applying theories from Greenberg (1963), Ruhlen (1975), Hawkins (1983), Tomlin (1986), and Dryer (2008).

This study was conducted in the English Education Masters Program at Sanata Dharma University, Yogyakarta. The researchers watched and transcribed the dialogues of the movies from a movie character, named Yoda. This character was chosen as purposive sampling by specifying features which met the goal of the research. There were seven movies where Yoda had screen time up to September 2018. See the table below for the list.

Table 1. Movies Where Yoda Appears

\begin{tabular}{lcl}
\hline No & Year Created & Title \\
\hline 1 & 1980 & Star Wars: Episode V - The Empire Strikes Back \\
2 & 1983 & Star Wars: Episode VI - Return of the Jedi \\
3 & 1999 & Star Wars: Episode I - The Phantom Menace \\
4 & 2002 & Star Wars: Episode II - Attack of the Clones \\
5 & 2005 & Star Wars: Episode III - Revenge of the Sith \\
6 & 2015 & Star Wars: Episode VII - The Force Awakens \\
7 & 2017 & Star Wars: Episode VIII - The Last Jedi \\
\hline
\end{tabular}

In order to analyze uncommon syntax produced by a movie character in Star Wars, named Yoda, the researchers observed the data results and findings. Based on significant studies in WO by Grennberg (1963), Ruhlen (1975), Howkins (1983), Tomlin (1986), and Dryer (2008), "the ranking SOV $>\mathrm{SVO}>\mathrm{VSO}>\mathrm{VOS}>\mathrm{OVS}>\mathrm{OSV}$ was categorized as the complete ranking". In this study, all of the dialogue transcripts were divided into four most uncommon VSO, VOS, OVS, and OSV WOs, and then analyzed to discover what factors affected the uncommon syntax utterance.

\section{RESULTS AND DISCUSSIONS}

\section{The VSO, VOS, OVS, and OSV Syntax}

This study aimed to analyze the uncommon syntaxes, uttered by Yoda in the Star Wars saga during his seven blockbuster runs. The verb-subject-object syntax, verb-object-subject syntax, object-subject-verb syntax, object-subject-verb syntax as the most four uncommon syntaxes found in the dialogues became the basis of this analysis. The findings were presented in Table 2 below. 
Table 2. The Use of OSV and VSO Syntax

\begin{tabular}{cc}
\hline Syntax & Frequency \\
\hline Verb-Subject-Object Syntax & 29 \\
\hline Verb-Object-Subject Syntax & 39 \\
\hline Object-Subject-Verb Syntax & 89 \\
\hline Object-Subject-Verb Syntax & 12 \\
\hline Total & 169 \\
\hline
\end{tabular}

As presented in Table 2, the researchers found 169 sentences in Yoda's dialogues with uncommon WO in syntax during his stint in seven movies. The Verb-Subject-Object syntax amounted to 29 sentences; wherein Verb-Object-Subject syntax occurred in 39 sentences. The Object-Subject-Verb syntax existed in 89 sentences wherein the Object-Subject-Verb syntax appeared into 12 sentences. Some of the sentences in dialogues were presented below in Table 3.

Table 3. Sentences in VSO, VOS, OSV, and OVS Syntax

\begin{tabular}{|c|c|c|c|}
\hline VSO & VOS & OSV & OVS \\
\hline Feel like what? & $\begin{array}{l}\text { Found someone you } \\
\text { have, I would say, } \\
\text { hmmm? }\end{array}$ & $\begin{array}{l}\text { A danger there is, of } \\
\text { losing who we are }\end{array}$ & Powerful Jedi was he. \\
\hline Away put your weapon! & Help you I can. & My home this is. & $\begin{array}{l}\text { Never his mind on } \\
\text { where he was, hmm? }\end{array}$ \\
\hline Stay and help you I will. & Take you to I will. & $\begin{array}{l}\text { My own counsel will I } \\
\text { keep on who is to be } \\
\text { trained }\end{array}$ & $\begin{array}{l}\text { The dark side of the } \\
\text { Force are they. }\end{array}$ \\
\hline Why wish you become Jedi? & $\begin{array}{l}\text { Quick to join you in a } \\
\text { fight. }\end{array}$ & $\begin{array}{l}\text { This one a long time have } \\
\text { I watched. }\end{array}$ & $\begin{array}{l}\text { For my ally is the } \\
\text { Force. }\end{array}$ \\
\hline Ready, are you? & $\begin{array}{l}\text { Consume you it will, as } \\
\text { it did Obi Wan's } \\
\text { apprentice. }\end{array}$ & $\begin{array}{l}\text { All his life has he looked } \\
\text { away to the future, to the } \\
\text { horizon. }\end{array}$ & And powerful ally it is. \\
\hline What know you ready? & $\begin{array}{l}\text { Hear you nothing that I } \\
\text { say }\end{array}$ & $\begin{array}{l}\text { Nothing more will I teach } \\
\text { you today. }\end{array}$ & Reckless is he. \\
\hline $\begin{array}{l}\text { For eight hundred years, have } \\
\text { I trained Jedi. }\end{array}$ & $\begin{array}{l}\text { If you leave now, help } \\
\text { them you could. }\end{array}$ & A domain of evil it is. & More to say have you? \\
\hline $\begin{array}{l}\text { If once you start down the } \\
\text { dark path, forever will it } \\
\text { dominate your destiny. }\end{array}$ & Save you it can. & In you must go. & $\begin{array}{l}\text { That not ready for the } \\
\text { burden were you. }\end{array}$ \\
\hline $\begin{array}{l}\text { Decide you must how to serve } \\
\text { them best. }\end{array}$ & Told you I did. & $\begin{array}{l}\text { Your weapons, you will } \\
\text { not need them. }\end{array}$ & $\begin{array}{l}\text { Anger, fear, } \\
\text { aggression, the dark } \\
\text { side are they. }\end{array}$ \\
\hline Stopped they must be. & $\begin{array}{l}\text { Revealed your opinion } \\
\text { is. }\end{array}$ & $\begin{array}{l}\text { Always with you it } \\
\text { cannot be done. }\end{array}$ & $\begin{array}{l}\text { Lies, deceit, creating } \\
\text { mistrust are his ways } \\
\text { now. }\end{array}$ \\
\hline
\end{tabular}

Table 3 showed that there were some comparisons between sentences which were initiated by an object (in OSV and OVS syntax) and verb (in VSO and VOS syntax). The 
sentences in OSV and OVS syntax were used in giving statements. A statement sentence could be used to declare a fact, opinion, or idea. A statement sentence is also called an assertive or declarative sentence. There is a period at the end of the sentence. Yoda used this OSV and OVS syntax to demonstrate his attitude and positivity about something. He mentioned the 'object' as the first part of his speech to show his strong opinions that influence related actions and remain persistent the entire time and in the side of persuasive messages. English is "a typical P1-SV-O language, topical constituents with Subject function have a great tendency to occur in clause-initial position" (Hannay, 1991, p. 142). "Finally, consider three instances of SVO languages, which are neither verb-final nor verb-initial, since the subject precedes the verb while the object follows the verb... Consider first English, which is SVO" (Dryer, 2007, p. 8), as in "The woman saw the dog," where the woman functions as S, saw as $\mathrm{V}$, and the $\operatorname{dog}$ as $\mathrm{O}$.

Note that the sentences in VSO and VOS syntax were used in giving commands. In English, a command sentence could be called an imperative form. Yoda used this kind of sentence when he wanted to tell someone to do something. The VSO and VOS syntaxes were also used to show Yoda's warnings. The warnings could be uttered by Yoda when there was something that made him conscious of possible riskiness. The warnings themselves could be weak or strong, in which, weak warning shared similarities to that of advice. To utter questions, Yoda also used the VSO and VOS syntax. A question sentence could be called interrogative sentence. Yoda applied this kind of syntax when he did not understand something and wanted to confirm things.

\section{Factors Affecting the Production of Uncommon Syntax}

From those seven movies, the factors of uncommon syntax production were also investigated to obtain in-depth understanding. There were three factors, namely the biography, the personality and traits, and the powers and abilities from Yoda as a character.

\section{The Biography}

Yoda was brought into the world 900 years before the Battle of Endor. He was portrayed as an outsider, an individual from a cryptic species. At that point he adapted Force energetically, he acclimatized the Jedi Order as a youngling. After experiencing the custom known as The Gathering, he was given Kyber precious stone to make his first lightsaber with help from Professor Huyang on board the Crucible. He and a Force-delicate companion were found and prepared by the Jedi Master N'Kata Del Gormo ("Yoda," n.d.a). By the age of 100, Yoda accomplished the position of Jedi Master. Having prevailed with regards to achieving the position of Mater, he went through the following eight centuries as mentor and guide of 
Jedi generations. It was assessed that over his lifetime, he mentored around 20,000 Jedi ("Yoda," n.d.b). In this way, his root and his age impacted the manner in which he accepted, though, and communicated with others.

\section{Personality and traits}

Yoda was perceived for his astuteness; he had gone through eight centuries educating and training Jedi generations throughout the ages ("Yoda," n.d.c). He was reluctant to consent to Anakin Skywalker or Luke Skywalker for Jedi mentoring, watching them inadequate. In the two circumstances, all things being equal, he let Obi-Wan Kenobi to persuaded him into inviting them as disciples.

At the point when Dooku incited an inadequate room fold all through his fight with Yoda on Geonosis, the Jedi, tested with the conceivable strategy of pursuing the escaping Sith or protecting the hurt Obi-Wan Kenobi and oblivious Anakin Skywalker from the falling debris, Yoda safeguarding his confidants instead of chasing down Dooku. In any case, when his companion Master Plo Koon's squadron was destroyed by the Confederate superweapon Malevolence, Yoda denied Anakin Skywalker and Ahsoka Tano to accompany Koon, alluding to the hazard set by the Separatist ship ("Yoda," n.d.d).

Yoda was capable of resist being convinced by the spirit of the dead Sith Lord Darth Bane, who had come into sight to him in a vision on the planet Moraband, identifying that the spirit was only a delusion and declined its summon to the dark side. As he was close to his demise before the Battle of Endor began, Yoda acquired his own mortality and the impending death toll and passed on uniting with the Force ("Yoda," n.d.e).

From Yoda's physical look, his ears were expressive and would now and again whirl when he was passing on compelling feelings like astonishment. His ears were also very sensitive. Regardless of his intensive Jedi tutoring and high kudos within the Order, he told that he privately had disapproval for ancient Jedi texts. He also was humorous and had a sense of curiosity. Even with his age and wisdom, he could playfully hunt through Luke's belongings when he first encountered him, quarreled R2-D2 for a torch, and laughed delightedly when he supposedly placed the ancient Jedi texts on fire, and discovering Luke's continued foolishness amusing, saying that he had "missed him".

Based on the dialogues, the creator of Yoda character wants to show that everything Yoda says is by all accounts a message of good, and the character appears to like imparting his insight and lessons to other people, as he is instructing learners notwithstanding when he is old. The manner by which Yoda treats others is as though he knows that he is significantly more dominant and more seasoned than the vast majority of different characters, yet he is not 
at all pompous (Korkiakoski, 2017). These personalities and traits make the character enjoyable so that the creator of Yoda's character might shape the way Yoda speaks became unique and remarkable.

\section{Power and Abilities}

As a Jedi Master, Yoda possessed some powers and abilities. Yoda was able to carry his own in battle against rivals such as the Sith Lords Count Dooku and Darth Sidious using his short green-bladed lightsaber. In his fight with Dooku on the planet Geonosis, Yoda was capable of forcing back different metal chunks and stone slabs that were thrown at him by his enemy and diverted a bombardment of Force lightning with just his palms, before attacking the Sith in a direct battle that ended with Dooku taking flight. He was on one moment in a position to telekinetically demobilize the Dark Jedi Asajj Ventress by just moving her weapons.

When Yoda challenged Darth Sidious in the Senate building, he directed the Sith flying through the air with a Force push and redirected a Senate linger husk that Sidious had thrown at him during their combat. Same with Dooku, Yoda also distracted Sidious' Force lightning raid using only his palms, even though the reaction energy increase created an outburst that threw both fighters apart. Regardless, the Jedi Master failed to win against Sidious and was forced to run for his life.

For the sake of teaching Luke Skywalker that anything was conceivable with the Force, Yoda skimmed his student's submerged ship out of a Dagobah bog and onto the dry ground with no obvious thing. He was additionally ready to end shelling from mammoths of living stone. During a fight with Confederate powers on the coral moon of Rugosa, Yoda cleared out a whole squad of droids without utilizing his lightsaber and ended three attack bowls and the infantrymen all alone ("Yoda," n.d.f).

Yoda could integrate and divert Force lightning with his palms. His power to use the quarrelsome practices of the Force in spite of, Yoda's unbelievably forceful relation to the Force associated with his many years of extensive study also gave him numerous additional abilities. During the trial of Quinlan Vos, Yoda divulged that he was able to discover the alignment of a Force-user just by tapping them ("Yoda," n.d.g). He also stated that the Force had allowed him to peruse the history of a life-force, could skillfully feel that he had fallen to the Dark Side even with Vos being skillful enough to obscure it from many other Jedi. While Yoda was physically isolated on Dagobah, he was capable of looking at other Jedis that were active in the Force, as well as he could not see one that had abandoned the beliefs of the Jedi. He could keep in his mind communicating with the Jedi Temples all over the galaxy and 
telepathically speak with any Jedi within them ("Yoda," n.d.h). He was also able to become proficient in preserving consciousness after death, a skill that Qui-Gon Jinn was unable to do, enabling him to demonstrate a visible existence rather than merely being a bodiless voice.

The other ability that Yoda had was abilities to experience Force visions. Nevertheless, he knew that Force prediction was not definite and that the future was always in motion. His visions guided him to forecast the collapse of the Jedi in the Clone Wars and even his death ("Yoda," n.d.i). Yoda was also illustrated to have a level of expertise in navigating despite often entrusting it to his armies, as when he was obliged to take a trip alone by Qui-Gon Jinn, Yoda showed his skill to navigate Anakin's interceptor relaxedly and was able to steer clear of inflicting any damage on it until he returned to the Jedi. As a Force inner being, Yoda was markedly capable of either controlling weather to create thunder or summoning lightning strikes himself.

From the details of Yoda's power and abilities, he was known as the best guru in the movies. The creator might intend to emphasize Yoda's superpowers with the way he spoke in uncommon syntax. Yoda was the only character in the movies who spoke in uncommon syntax. Therefore, the image of Yoda's character could not be replaced by other characters in the movies.

\section{CONCLUSION}

Based on the findings and discussion, the researchers concluded that a Star Wars character named Yoda produced uncommon WO in syntax in seven blockbuster movies of Star Wars. In spite of the utterances, the contextual meanings of the sentences, which are mostly in SOV and SVO, remained the same as that of basic WO. The word choice of Yoda was also common in English. Related to his biography, personalities, and abilities, the creator of the Saga, George Lucas, intended to make the way Yoda spoke become unique and remarkable. Yoda was the only character in the saga who spoke in uncommon syntax. Therefore, the image of Yoda's character could not be replaced by other characters in the saga, as well as in other movies. At last, this study would benefit a group of people, such as linguists, movie producers/scriptwriters, and language teachers who tackle syntactic rules in English.

\section{REFERENCES}

Ary, D., Jacobs, L. C., \& Razavieh, A. (2002). Introduction to research in education (6th ed.). Wadsworth: Thomson Learning. 
Ary, D., Jacobs, L. C., Sorensen, C., \& Razavieh, A. (2010). Introduction to research in education (8th ed.). Belmont, CA: Wadsworth Cengage Learning.

Bailey, L.R. (2010). Sentential word order and the syntax of question particles. Newcastle Working Papers in Linguistics, 16(1), 23-43.

Bauer, L. (2007). The linguistics student's handbook. Edinburgh: Edinburgh University Press.

Creswell, J. (2007). Qualitative inquiry \& research design: Choosing among five approaches 2nd ed. California: Sage Publication

Derbyshire, D. C. (1977). Word order universals and the existence of OVS languages. Linguistic Inquiry, 8(3), 590-599.

Djami, C. B. N., Setiawan, N. A., \& Bram, B. (2019). The use of notional and grammatical agreement of semester 1 English language education study program's students. The 5th International Language and Language Teaching Conference Proceedings. Sanata Dharma University, Yogyakarta. Retrieved from https://drive.google.com/file/d/1oQpcFi5hZoCR95C4yuEc3rxhDoiJpcLT/view

Dryer, M. S. (2007). Word order. Language Typology and Syntactic Description, 1, 61-131.

Dryer, M. S. (2008a). The branching direction theory of word order correlations revisited. In Scalise, S., Magni, E., \& Bisetto, A. (Eds.). Universals of Language Today. Berlin: Springer.

Dryer, M. S. (2008b). Word order in Tibeto-Burman languages. Linguistics of the TibetoBurman Area, 31(1), 1-83. Retrieved from https://www.acsu.buffalo.edu/ dryer/DryerTibetoBurmanWordOrder.pdf

Greenberg, J. (1963). Some universals of grammar with particular reference to the order of meaningful elements. In J. Greenberg (Ed.), Universals of Language. Cambridge, MA: Massachusetts Institute of Technology.

Hannay, M. (1991). Pragmatic function assignment and word order variation in a functional grammar of English. Journal of Pragmatics, 16(2), 131-155. https://doi.org/10.1016/0378-2166(91)90077-B.

Hawkins, J. (1983). Word order universals. New York: Academic.

Iwashita, N. (2010). Features of oral proficiency in task performance by EFL and JFL learners. In Selected Proceedings of the 2008 Second Language Research Forum, ed. Matthew T. Prior et al., 32-47. Somerville, MA: Cascadilla Proceedings Project.

Izadi, M., \& Rahimi, M. (2015). Word order of Persian and English: A processing-based analysis. Education Journal. 4(1), 2327-2619. doi: 10.11648/j.edu.20150401.18

Kaiser, E., \& Trueswell, J. C. (2004). The role of discourse context in the processing of a flexible word-order language. Cognition, 94(2), 113-147. https://doi.org/10.1016/j.cognition.2004.01.002.

Korkiakoski, I. (2017). Yoda the powerful jedi master: Perception of the character of Yoda in five of the first six Star Wars films. (Bachelor Thesis). The University of Oulu. Retrieved from http://jultika.oulu.fi/files/nbnfioulu-201706082641.pdf

Maurits, L. (2011). Representation, information theory and basic word order. Dissertation. School of Psychology. The University of Adelaide. Retrieved from https://digital.library.adelaide.edu.au/dspace/bitstream/2440/74128/8/02whole.pdf 
McCawley, J. D. (1970). English as a VSO language. Language, 46(2), 286-299. DOI: $10.2307 / 412279$.

Newmeyer, F. J. (1998). Language form and language function. Cambridge, MA. Massachusetts Institute of Technology.

Radford, A. (2004). English syntax: An introduction. Cambridge: Cambridge University Press.

Ruhlen, M. (1975). A guide to the languages of the world. Stanford, Online Computer Library Center (OCLC): 1940981.

Tomlin, R. S. (1986). Basic word order: Functional principles. London: Croom Helm.

Yoda. (n.d.). Retrieved from https://starwars.fandom.com/wiki/Yoda/Legends

Zhao, G., \& Cao, Z. (2016). Contrastive study of English and Chinese word order from the perspective of figure-ground theory - a case study of the moonstone and its Chinese version. Journal of Language Teaching and Research, 7(2), 389-397. doi: http://dx.doi.org/10.17507/jltr.0702.20 